\title{
Design and Analysis of Battery Electric Vehicle Sprayer Chassis by Using Finite Element Method
}

\author{
D. S. Karale ${ }^{1}$, Dr. S. H. Thakre ${ }^{2}$, Dr. V. P. Khambalkar ${ }^{3}$, Dr. M. M. Desmukh ${ }^{4}$, R. D. Walke \\ ${ }^{I}$ Ph. D. Scholar, Deptt. of FPM, Dr. PDKV Akola \\ ${ }^{2}$ Professor and Head Deptt. of FPM, Dr. PDKV Akola \\ ${ }^{3 \& 4}$ Assistant Professor, Deptt. of FPM, Dr. PDKV Akola \\ ${ }^{5}$ Associate Professor, Deptt. of Agril. Economics and Statistic \\ Collage of Agriculture, Dr. PDKV Akola
}

DOI: 10.46335/IJIES.2020.5.11.3

\begin{abstract}
The chassis of the BEV sprayer was design and developed based on assumptions made on gross weight of the vehicle for carrying the suitable size of sprayer attachment. The e validation of design was made by using Finite Element Method (FEM) with the help of ANSIS software. For analysis of chassis different loading conditions as self-load of the vehicle and boom sprayer load was considered. The FEM analysis was done to validate the design consideration and assumption used during design procedure. Before the modifications in the FEM analysis it was observed that the $2 \mathrm{~mm}$ thickness of the design chassis cross members was found weaker which was modified as $3 \mathrm{~mm}$ and further analyzed. From the FEM analysis it was observed that $3 \mathrm{~mm}$ thickness of the beam was suitable for the BEV sprayer. The least maximum bending moment was observed as $0.144 \mathrm{~mm}$ with $3 \mathrm{~mm}$ thick rectangular hallow section which was safe for the fabrication work of BEV chassis hence, a rectangular section of 50x42 size was selected. The CAD system with ANSYS software was found suitable to reduce time required for repetitive design calculation, fabrication, assembling work during the actual entire fabrication process.
\end{abstract}

Keywords- BEV, Sprayer, Chassis and FEM

\section{I- INTRODUCTION}

$\mathbf{T}_{\mathrm{h}}$ components attached to machine but also to make the vehicle robust and strong enough to withstand all the forces acting on the vehicle. The BEV chassis is need to be develop based on assumptions made on gross weight of the vehicle for carrying suitable size of sprayer attachment by considering the agronomical requirements of the field crops available in the region. Many researchers viz. Caner Koc,2017;K. S. J. Prakash 2016; Awate, 2016 and many more suggested that the chassis needto be design by considering necessary assumptions of the gross weight of the vehicle and validate and improve their designs by using Finite Element Method in their investigation(Ravi Kumar, 2018; Remesh Kumar, 2018 and Hari Kumar, et al. 2016). Finite element system enables one to rapidly spot problem areas and it redesign our product without the costly rework and re-fabrication, thus savingtime and money. For the purpose of FAE, the Von Misses stress failure criterion was used which basically tests the stress at which the material begins to yield. As reported Ramesh, 2017 the Von Misses stress is considered to be a safe haven for design engineers. Using this information an engineer can say his design will fail, if the maximum 
value of Von Misses stress induced in the material is more than strength of the material. It works well for most cases, especially when the material is ductile in nature. For this the required assumptions based on the weight of the vehicle will be taken in to consideration during the manually calculating the forces. Which need to be validated by Finite Element Method (FEM) by using ANSIS software. Such type of analysis of chassis is essential by considering various load acting on body which were not accounted during the manual calculations which is helpful to avoid failure of chassis.

Kipping this view, the present study was conducted to validate the design of chassis by using Finite Element Method (FEM) by using ANSIS software.

\section{II - MATERIAL AND METHODS}

\section{Design calculations for BEV chassis}

In a proposed machine width of machine was finalized based on the reviews, agro-technical requirements and differential technical parameters. The width of chassis was considered with the $45 \mathrm{~cm}$ and $60 \mathrm{~cm}$ row spacing. For proper balancing of two-wheel vehicle with the boom arrangement and maneuverability point of view for turning at headland the wheel supports of $1000 \mathrm{~mm}$ at drive wheel and at the front with caster wheels of $1560 \mathrm{~mm}$ were provided. So, after considering leverage effect a total length as $1560 \mathrm{~mm}$ was finalized. After finalization of width, chassis was considered as single point support overhangs beam. The uniform distribution of the load is as shown in 1

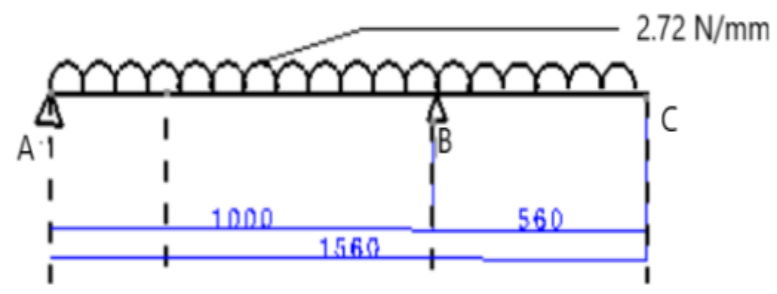

Fig. 1 Uniformly destitution of load on chassis

The tubular section has less weight as compared to solid and other section of the mild steel material. The material and geometry for BEV chassis as given below Table 1 .

Table 1- Material and Geometry for BEV chassis

\begin{tabular}{|l|l|l|}
\hline $\begin{array}{l}\text { Sr. } \\
\text { No. }\end{array}$ & Particulars & Details \\
\hline $\mathbf{1}$ & $\begin{array}{l}\text { Side bar of the } \\
\text { chassis }\end{array}$ & $\begin{array}{l}\text { Made from hollow } \\
\text { rectangular tubular pipes } \\
\text { with } 50 \mathrm{~mm} \times 46 \mathrm{~mm}\end{array}$ \\
\hline
\end{tabular}

\begin{tabular}{|c|c|c|}
\hline 2 & $\begin{array}{l}\text { Material of the } \\
\text { chassis }\end{array}$ & Mild Steel \\
\hline 3 & Rear Overhang & $1000 \mathrm{~mm}$ \\
\hline 4 & Beam spam & $1560 \mathrm{~mm}$ \\
\hline 5 & Support Spam & $560 \mathrm{~mm}$ \\
\hline 6 & Wheel base & $838 \mathrm{~mm}$ \\
\hline 7 & $\begin{array}{l}\text { Modulus of } \\
\text { Elasticity, E }\end{array}$ & $2.10 \times 10^{5} \mathrm{~N} / \mathrm{mm}^{2}$ \\
\hline 8 & Poisson Ratio & 0.28 \\
\hline 9 & Capacity of BEV & $150 \mathrm{~kg}(1471.5 \mathrm{~N})$ \\
\hline 10 & $\begin{array}{l}\text { Capacity of BEV } \\
\text { with } 1.25 \%\end{array}$ & $1839.37 \mathrm{~N}$ \\
\hline 11 & $\begin{array}{l}\text { Weight of the body } \\
\text { and motor and } \\
\text { components }\end{array}$ & $245.93 \mathrm{~kg}(2412.63 \mathrm{~N})$ \\
\hline 12 & $\begin{array}{l}\text { Total load acting } \\
\text { on chassis }\end{array}$ & $\begin{array}{l}\text { Capacity of the Chassis }+ \\
\text { Weight of body and engine } \\
=1839.37+2412.63= \\
4252 \mathrm{~N}\end{array}$ \\
\hline
\end{tabular}

The BEV Chassis has two beams. So, load acting on each beam is half of the total load acting on the chassis. $\frac{\text { Total load acting on chassis }}{\text { Number of beams }}$ Eq. 1

$$
=\frac{4252}{2}=2126 \mathrm{~N}
$$

Analysis of reaction

Beam is simply clamp with shock absorber. Therefore, the beam is considered as a simply supported beam. Supported at B and $\mathrm{C}$ with uniform distributed load.

Load acting on the entire span of the beam $=4252 \mathrm{~N}$ and Length of the beam $=1560 \mathrm{~mm}$. Fig. 2 shows the rectangular hollow section for which moment of inertia can be calculated as

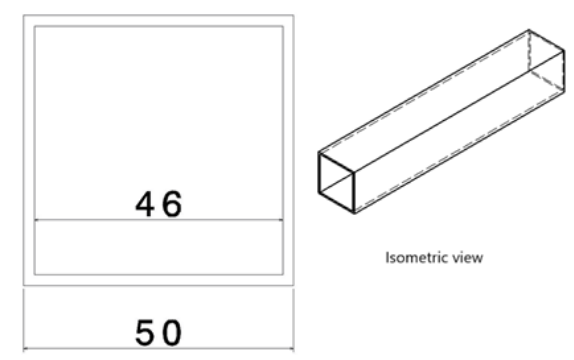

Fig.2- Hollow rectangular section

$$
I=\frac{a^{4}-b^{4}}{12} \mathrm{Eq} .2
$$

By putting the values for $\mathrm{a}$ and $\mathrm{b}$ as 50 and 46 $\mathrm{mm}$ in equation 2 we have

$$
\begin{aligned}
& I=\frac{50^{4}-46^{4}}{12} \\
& =147712 \mathrm{~mm}^{4}
\end{aligned}
$$


Now the total load acting on chassis is assumed to be uniformly distributed on the entire spam of the beam as shown in Fig. 1. Hence uniformly distributed load is calculated as

$$
\begin{gathered}
\begin{array}{l}
U d l= \\
\frac{\text { Total load acting on beam span }}{\text { Length of beam }} \\
\text { Eq. } 3
\end{array} \\
=\frac{4252}{1560}=2.72 \mathrm{~N} / \mathrm{mm}
\end{gathered}
$$

There are two beams in the chassis hence load on the single beam is half of the uniformly distributed load i.e. $1.36 \mathrm{~N} / \mathrm{mm}$. For design consideration taking a factor of safety as 2 . Hence, the total uniformly distributed load on the beam is considered as $2.72 \mathrm{~N} / \mathrm{mm}$ from safety point of view for calculating stress induced and bending moment. For calculating bending moments and stress in simply supported overhang beam with uniform distribution of load following formulas were used. (Anonymous,2005).

$$
\begin{aligned}
& R_{1}=V_{1}=\text { rection at point } A=\frac{w}{2 l}\left(l^{2}-\right. \\
& \left.a^{2}\right) \text { Eq. } 4
\end{aligned}
$$

Now putting the value from Fig. 1 in equation 4 for calculating the rection at point $\mathrm{A}$ we have

$$
\begin{gathered}
R_{1}=V_{1}=\frac{w}{2 l}=\left(l^{2}-a^{2}\right) \\
=\frac{2.72}{2 \times 1000}=\left(1000^{2}-560^{2}\right) \\
R_{1}-V_{1}=933.54 \mathrm{~N}
\end{gathered}
$$

Rection generated at point $\mathrm{B}$ due to load acting on beam is given by

$$
R_{2}=V_{2}+V_{1}
$$

$$
\begin{aligned}
& =\frac{w}{2 l} \\
& \times\left(l^{2}+a^{2}\right)
\end{aligned}
$$

By putting the value in equation 5 we have

$$
\begin{aligned}
R_{2}=\frac{2.72}{2 \times 1000} & \times\left(1000^{2}+560^{2}\right) \\
& =1786.49 \mathrm{~N}
\end{aligned}
$$

Now calculating the shear force at point, A and B we have

$$
V_{2}=w a \text { Eq. } 6
$$

By putting the values from Fig. 1 in equation 6 we have

$$
\begin{gathered}
V_{2}=2.72 \times 560=1523.2 \mathrm{~N} \\
V_{1}=\frac{w}{2 l} \times\left(l^{2}+a^{2}\right) \text { Eq. } 7 \\
=\frac{2.72}{2 \times 1000} \times\left(1000^{2}+560^{2}\right) \\
=1786.49 \mathrm{~N}
\end{gathered}
$$

Now $V_{x}$ between support is given by

$$
V_{x}=R_{1}-
$$

$w x$

Eq. 8

Assume the $x=\frac{l}{4}=560 \mathrm{~mm}$

$$
\begin{array}{r}
V_{x}=933.54-2.72 \times 560 \\
=253.54 \mathrm{~N}
\end{array}
$$

Now calculating the $\mathrm{V}_{\mathrm{x} 1}$ for overhang assume the $x_{1}=\frac{l_{1}}{4}=140 \mathrm{~mm}$

$$
\begin{gathered}
V_{x 1}=w\left(a-x_{1}\right) \text { Eq. } 9 \\
V_{x 1}=2.72(560-140) \\
V_{x 1}=1142.4 \mathrm{~N}
\end{gathered}
$$

Now determining the maximum bending moment, we have

$\mathrm{M}_{1}$ is the bending moment at $\mathrm{R}_{1}$ which is given by

$$
\begin{aligned}
& M_{1} \\
& =\frac{w}{8 l^{2}}\left((l+a)^{2}(l\right. \\
& -a)^{2}
\end{aligned}
$$

By putting the values from Fig. 1 in equation 10 we have

$$
\begin{aligned}
M_{1}= & \frac{2.72}{8 \times 1000^{2}}(1000+560)^{2} \\
& \times(1000-560)^{2} \\
M_{1}= & 160.18 \mathrm{~N}-\mathrm{m}
\end{aligned}
$$

$\mathrm{M}_{2}$ is the bending moment at $\mathrm{R}_{2}$ which is given by

$$
\begin{aligned}
& M_{2} \\
& =\frac{w a^{2}}{2} \\
& M_{2}=\frac{2.72 \times 560^{2}}{2} \\
& M_{2}=426.49 \times 10^{3}
\end{aligned}
$$

Now calculating $\mathrm{M}_{\mathrm{x}}$ between support we have

$$
\begin{aligned}
& M_{2} \\
& =\frac{w x}{2 l}\left(l^{2}-a^{2}\right. \\
& -x l)
\end{aligned}
$$

Therefore, by putting the values in equation 12 we have

$$
\begin{aligned}
M_{2}= & \frac{2.72 \times 250}{2 \times 1000} \\
& \quad \times\left(1000^{2}-560^{2}-250 \times 1000\right) \\
M_{2}= & 148.37 \times 10^{3} \mathrm{~N}-\mathrm{mm}
\end{aligned}
$$

Now calculating the bending moment at point $\mathrm{x}$ is given by

$$
\begin{aligned}
& M_{x 1} \\
& =\frac{w}{2}\left(a-x_{1}\right)^{2} \\
& M_{x 1}=\frac{2.72}{2}(560-140)^{2} \\
& M_{x 1}=239.90 \times 10^{3} \mathrm{~N}-\mathrm{mm}
\end{aligned}
$$

To find the deflection between support we have,

$$
\begin{aligned}
& \Delta x=\frac{w x}{24 E I}\left(l^{4}-2 l^{2} x^{2}+l x^{3}-2 a^{2} l^{2}+\right. \\
& \left.2 a^{2} x^{2}\right) \text { Eq. } 14
\end{aligned}
$$




$$
\begin{aligned}
\Delta x=\frac{2.72}{} \times \frac{250}{24200 \times} & 10^{6} \times 147712 \\
- & 2 \times 1000^{2} \times 250^{2} \\
& +1000 \times 250^{3}-2 \\
& \times 560^{2} \times 1000^{2} \\
+ & \left.2 \times 560^{2} \times 250^{2}\right)
\end{aligned}
$$

$\Delta x=0.187978 \mathrm{~mm}$

Now determine the deflection between overhang area we have

$$
\begin{aligned}
\Delta x_{1}=\frac{w x_{1}}{24 E I}\left(4 a^{2} l-l^{3}+6 a^{2} x_{1}-4 a x_{1}^{2}+x_{1}^{3}\right) \\
\Delta x_{1}=\frac{2.72 \times 140}{24 \times 200} \times 10^{6} \times 147712 \\
\times 1000-1000^{3}+6 \times 560^{2} \\
\times 140-4 \times 560 \times 140 \\
\left.\times+140^{3}\right)
\end{aligned}
$$

$\Delta x_{1}=-0.06799 \times 10^{-9} \mathrm{~mm}$

Hence overhang beam generating two deflection are critical, one is $+\mathrm{Ve}$ deflection and other is $-\mathrm{Ve}$ deflection. In +ve deflection it considers that load acting in compression ie. In upper portion so that the region bending moment created is $+\mathrm{Ve}$ direction. Meanwhile in overhanging portion in upper portion is subjected to tensile load and bottom portion is subjected to the compression load so deflection created shown in -Ve sign. The details of the sheer force and bending moment diagram is illustrated in Fig. 3

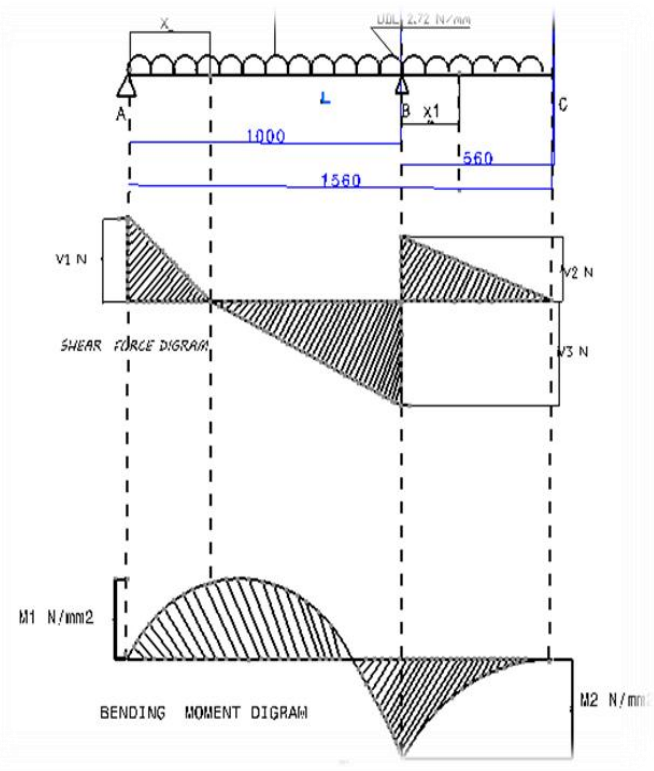

Fig.3-Shear force and bending moment diagram for chassis beam.

\section{FEA Analysis of Chassis}

Finite Element Analysis (FEA) is a technic those are used for the e validation of design while applying various forces on the BEV chassis because of which most critical stresses area and deformation are easily identified.

The FEA was done to check if the designed chassis on certain load would be capable of handling the stresses of loading conditions of the vehicle. The Fig. 4 shows the loading boundary conditions of chassis. After that the static analysis is used to determine the displacement, stresses induced, strain forces in components or structure of chassis caused by the load in Y-component that do not induce significant inertia and damping effects. The boundary conditions are fixed at support and pressure load of $3681 \mathrm{~N}$ is applied on the chassis area without boom load, in addition to this boundary conditions are fixed for a chassis with boom load with adding the pressure load in Y-component of $371 \mathrm{~N}$.

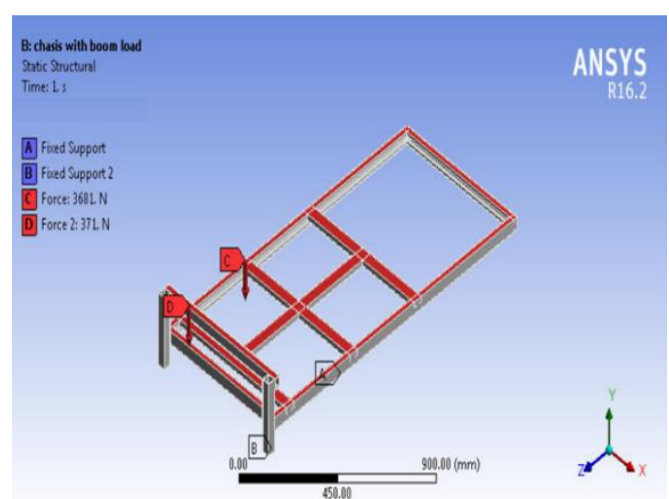

Fig. 4-Details of the loading boundary conditions on chassis

\section{III-RESULT AND DISCUSSION}

\section{Meshing of chassis}

Fig. 5 shows the CAD model geometry and its meshing. From Fig.5 it was observed that meshing is done with 722936 node solids and 359928 elements in chassis without boom load. Whereas in case of chassis with boom load the meshing is done with 888068 nodes and 447393 elements.

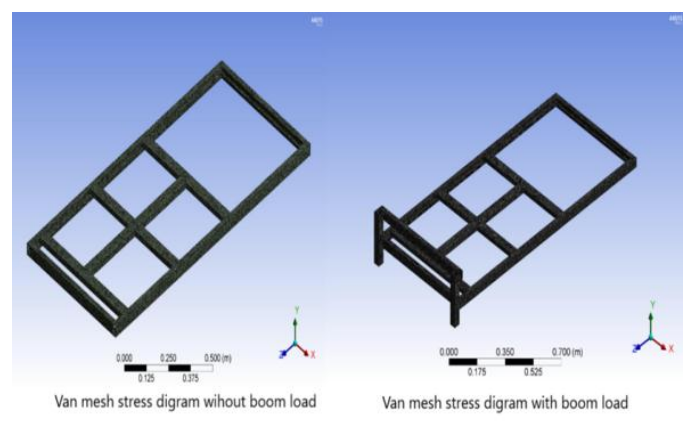

Fig. 5 - Illustration of meshing results with and without boom load conditions of chassis 


\section{Total deformation in chassis before modification}

After mesh generation the actual behavior of chassis material of the battery electric vehicle was evaluated by considering it as static structure. Fig. 6 shows the maximum deformation values were obtained at $0.53 \mathrm{~mm}$ and $0.55 \mathrm{~mm}$ for chassis without boom load and with boom load respectively

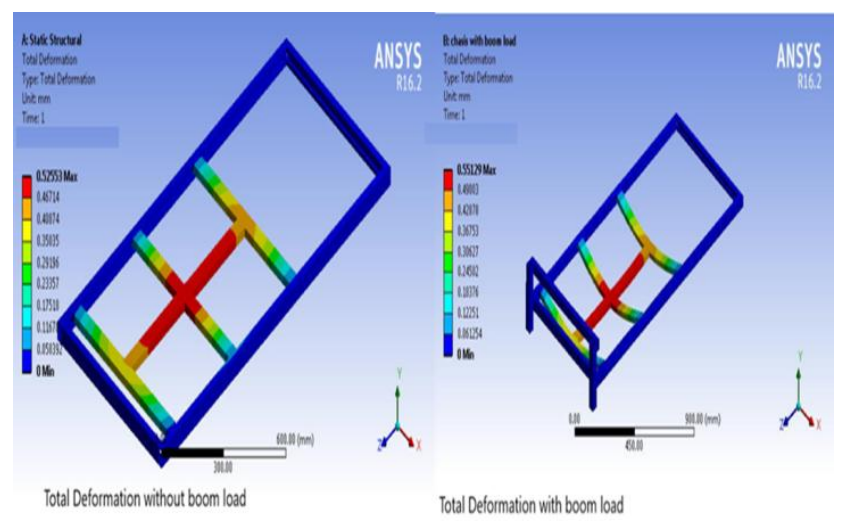

Fig. 6 Total deformation without and with boom load in chassis before modification

When battery electric vehicle sprayer works with boom the total deformation values observed as $0.55 \mathrm{~mm}$ while the no any deformation in side elements of the chassis. From Fig. 6 it clearly show that deformation occurred in body of BEV chassis is in controlled condition, it means it is safe for further working but for with boom load it is in higher side and frame was shown in curved shape.

Equivalent Von-Mesh Stress in chassis before modification

The analysis of the static structure for equivalent von misses during the BEV chassis without and with boom load conditions, total equivalent van misses stress developed for such conditions was illustrated in Fig. 7. It is noted that maximum van mesh equivalent stress developed is $71.46 \mathrm{MPa}$ and minimum is $3.728 \mathrm{e}^{-8} \mathrm{Mpa}$ for chassis. Whereas the maximum Von misses mesh equivalent stress developed is $69.56 \mathrm{MPa}$. There was slight curve portion seen in the equivalent Von misses stress diagram. It was observed that while considering boom load some slight change will happen the stress to reach up to 69.56 Mpawhich is less than previous so it's also indicates in Von misses stress this is safe for working condition but in case of with boom load it observed quite high.

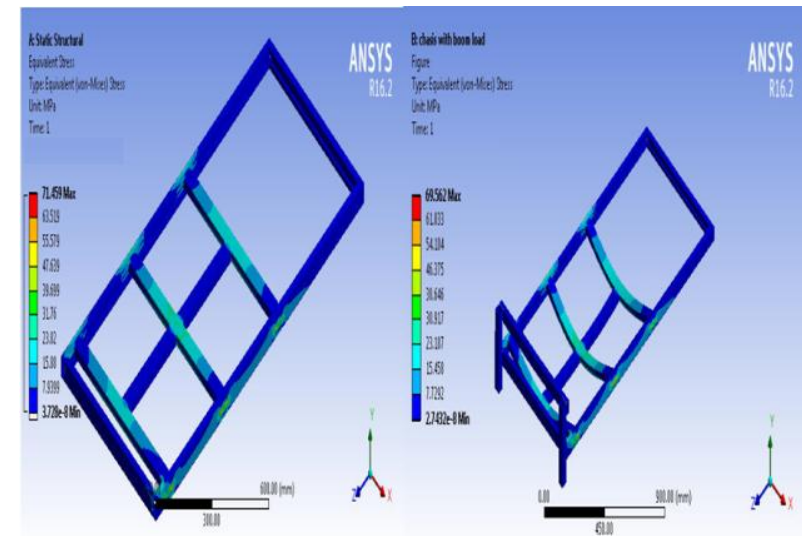

Fig. 7- Equivalent Von-Mises Stress in chassis before modification

Equivalent Elastic Strain in chassis before modification

The equivalent electric strain is very important parameter for validation of design. The equivalent strain developed in the chassis components is as shown in Fig 8 with different colour coding for without and with boom load. The maximum equivalent elastic strain values obtained for chassis with boom load was 0.0004 $\mathrm{mm} / \mathrm{mm}$ and minimum value was $4.0282 \mathrm{e}^{-13} \mathrm{~mm} / \mathrm{mm}$. Whereas the chassis without boom load condition has maximum equivalent elastic strain of $0.00036 \mathrm{~mm} / \mathrm{mm}$ and the minimum value is $9.0486 \mathrm{e}^{-13} \mathrm{~mm} / \mathrm{mm}$.

Fig. 8 Equivalent elastic strain in chessis in

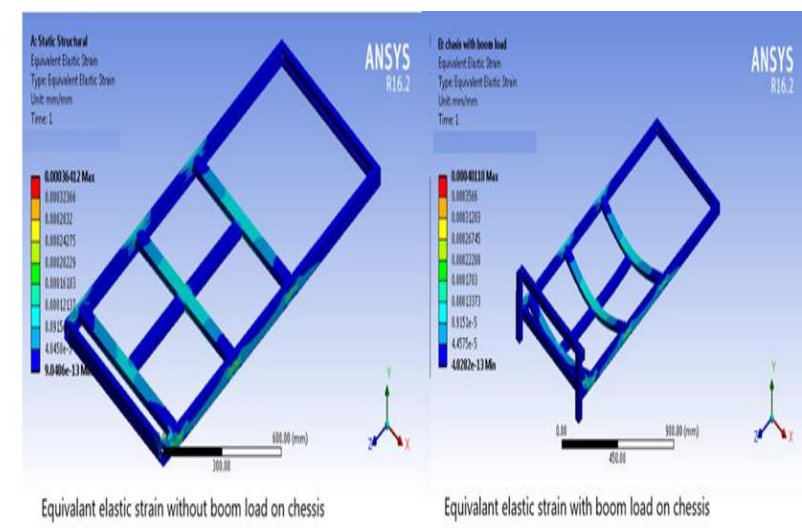

Fig. 8 Equivalent elastic strain in chessis in chassis before modification

Overall the maximum value deformation value is 0.55 $\mathrm{mm}$ over the total length. Maximum van mesh equivalent stress developed was noted as $71.46 \mathrm{MPa}$. The maximum equivalent elastic strain obtained in chassis with boom load was $0.0004 \mathrm{~mm} / \mathrm{mm}$.

After observing the above results those are subjected to for $2 \mathrm{~mm}$ thick square hollow section as discussed in 
section 2.1 the support elements of the during analysis chassis found somewhat weaker to sustained the load of the vehicle with boom arrangement. For the avoiding such kind of trouble it is decided to upgrade the thickness of hallow pipe from $2 \mathrm{~mm}$ to $3 \mathrm{~mm}$ for chassis. By keeping all dimension of frame is same only internal side thickness was changed. After that re-validated is consider for observing the stress induced and bending moment in the modified chassis for which similar procedure was adopted and the result obtained as discussed below.

\section{Total Deformation in modified Chassis}

The total deformation in the modified chassis was evaluated without boom load and with boom load conditions. Fig.9 shows the total deformation values in colour coding. From Fig.9 it was observed that the maximum total deformation was in the range of 0 to 0.14 $\mathrm{mm}$ in modified chassis without boom load. Adding boom load on the chassis the values for deformation was observed in the range of 0 to $0.144 \mathrm{~mm}$.

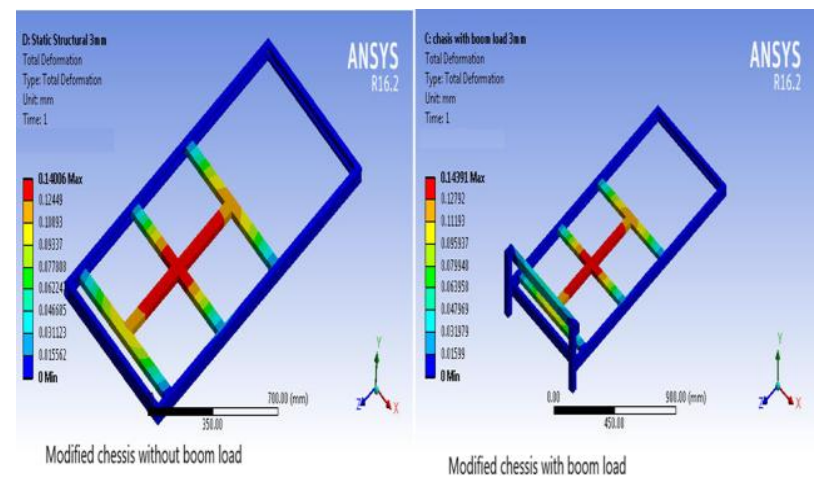

Fig. 9 Total deformation diagram for modified chassis

\section{Equivalent Von Misses Stress in modified Chassis}

The modified chassis was subjected to with and without boom load conditions to observe the equivalent von misses stress developed in the chassis. Fig. 10 illustrated van mises stresses developed in the chassis components with different color coding. From Fig 10 it was observed that equivalent elastic strain developed without boom load was in the range of $9.9353 \mathrm{e}^{-13}$ to $19.044 \mathrm{MPa}$. While in boom load conditions it was in the range of $7.6006 \mathrm{e}^{-13}$ to $20.557 \mathrm{MPa}$. Fig. shows that the maximum values in red color was observed where the cross member and beam of chassis were welded.

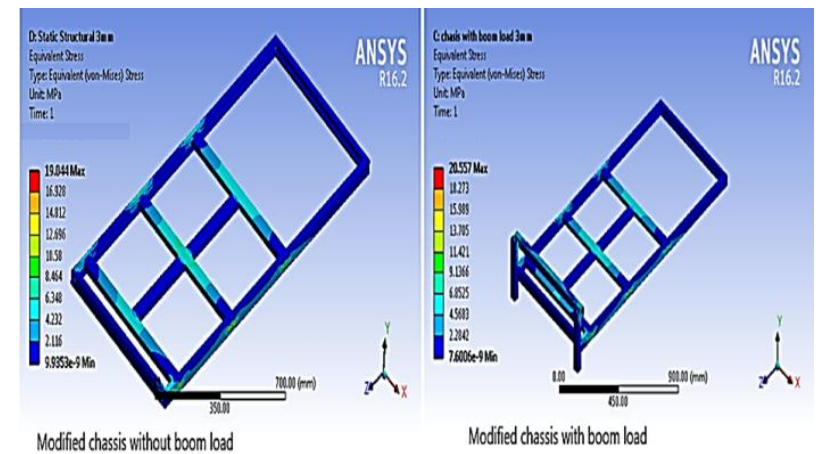

Fig. 10 -Equivalent Von Mises stress diagram for modified chassis

\section{Equivalent Elastic strain in modified chassis}

The modified chassis is subjected to find out equivalent elastic strain developed in the modified chassis. The results obtained for the same is illustrated in Fig. 11 Fig . shows the color-coded strain values minimum in blue color to maximum as in red color. The chassis without boom load condition, the equivalent elastic strain was in the range of $2.4115 \mathrm{e}^{-13}$ to $9.7039 \mathrm{e}^{-5} \mathrm{~mm} / \mathrm{mm}$. While with boom load condition the values were in the range of 1.9365 e-9 to $0.00011264 \mathrm{~mm} / \mathrm{mm}$.

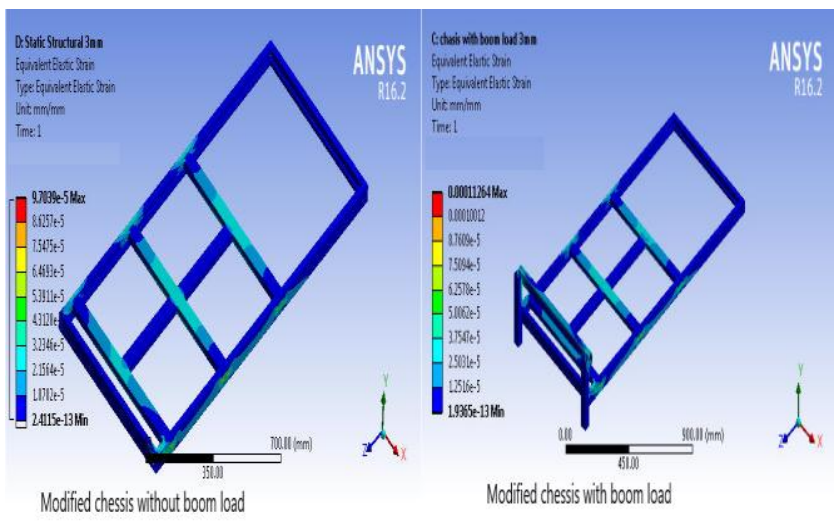

Fig. 4.6 -Equivalent Elastic strain diagram for modified chassis

\section{IV-CONCUSSIONS}

The battery electric vehicle spryer operated along with the spray boom hence it is important that total load with boom is need to be in the design. From the results obtained the various conclusions were drawn as follows

1. As discussed in section 2 the theoretical design calculation shows that the maximum deformation occurred in the frame was 0.188 $\mathrm{mm}\left(\Delta \mathrm{x}_{1}\right)$ for the $2 \mathrm{~mm}$ thick hollow rectangular sanction of the chassis.

2. The computer added design was subjected for the same for FEA by using ANSYS R 16.2 
software and the maximum value are obtained with boom load conditions for bending moment is $0.55 \mathrm{~mm}$. The difference in theoretical and software bases result is varied also the \% error obtained from this value was so large it's not in controllable condition. So, the next decision of increase in thickness from $2 \mathrm{~mm}$ to $3 \mathrm{~mm}$ was game changers.

3. Instead of changing the all dimensions onlyincreasing the thickness of $2 \mathrm{~mm}$ to $3 \mathrm{~mm}$ was observed with satisfied all conditions.

4. The least maximum bending moment is observed as $0.144 \mathrm{~mm}$ with $3 \mathrm{~mm}$ thick rectangular hallow section which was safe for the fabrication work of BEV chassis hence, a rectangular section of 50x42 size was selected.

5. From the above it was concluded that CAD system with ANSYS software was found suitable to reduce time required for repetitive design calculation, fabrication, assembling work during the actual entire fabrication process.

6. From above it was observed that the deformation in theoretical case is more than practical case. So , the modified design was safe for carrying all load on chassis.

\section{REFERENCES}

[1] Hari Kumar A.,and DeeanjaliV. (2016). Design and analysis of automobile chassis. International Journal of Engineering Science and Innovative Technology, Vol. 5 (1), pp. 187-196.

[2] Anonymous (2005). Beam design formulas with shear and moment diagram Published by American Forest and Paper Society Association Inc. Washington, DC. Available at www.awc.org.

[3] KocCaner (2017). Structural analysis of field sprayer booms. TartmBilimleri Dergisi Journal of Agricultural Sciences, 23., pp.147-155.

[4] Haresh K., Vaniya V. D., ArvindSonara., and SorthiyaS. (2015). Analysis of backhoe loader chassis for weight \& cost reduction using FEA - A review paper. International Journal for Innovative Research in Science \& Technology., Vol. 1 (8)., pp. 1-8.

[5] Prakash K. S. J., and Srikanth A. (2016). Static and dynamic stress analysis of auto chassis and crank shaft using ANSYS. International Journal of Advanced Scientific Technologies in Engineering and management Sciences., Vol. 2 (11), pp. 26-30.
[6] Ramesh M. V. G., Vijay Kumar and Diwakar G. (2017). Design and fabrication of solar electrical vehicle system. IJSER., Vol. 8(6) pp. 1719-1727.

[7] Munish Kumar (2018). FEM analysis of a flatbed semi-trailer chassis structure ,International journal of Research and Analytical Reviews, Vol. 5 (2) pp. $1826-1831$

[8] Awate Nilesh and Tidke D. J., (2016) Modeling and Optimization of a Mobile Crop Residue Disintegrator. International Journal of Mechanical Engineering and Technology, 7(3), pp. 320-328.

[9] Ravi Kumar Panthangi, ShaikAkhibSohail and V. V. Kondaiah (2018). Static structural analysis of an advanced power tiller chassis and chisel plough. International journal of Mechanical and Production Engineering Research and Development Vol. 8 (5), pp. 299-304.

[10] Venukumar R. Bankapur and Sanjeev. A. Janawade (2015). Fatigue analysis tractor trailer chassis. International Research Journal of Engineering and Technology, Vol. 2(3)., pp. 1583-1588. 